\title{
Employee Perceptions on Ethics, Racial-Ethnic and Work Disparities in Long-Term Care: Implications for Ethics Committees
}

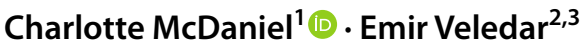

Accepted: 22 December 2020 / Published online: 31 January 2021

(c) The Author(s), under exclusive licence to Springer Nature B.V. part of Springer Nature 2021

\begin{abstract}
This study explored the perceptions of ethics among long-term care employees (N275) in order to test two hypotheses. A cohort cross-sectional survey examined employees' perceptions of an ethics environment, racial-ethnic, and position disparities (HO1; ANOVA), and, secondarily, ethics in relationship to select, researchgrounded work features measured as manage disagreements, effectiveness, work satisfaction, and opinions of care, the latter including intention to remain (HO2; Pearson Correlations). Established questionnaires with robust psychometrics were employed. Response rate was $51 \%$. Non-significant differences between sample and population on key variables supported extrapolation of results. Statistically significant differences between racial-ethnic $(p<0.03 ; F 2.42)$ and work positions $(p<0.0001 ; F$ 6.24) were revealed on ethics (3.16; HO1). Statistically significant relationships $(p<0.0001 ; r=0.26-0.68$; HO2) between ethics and employees' work features also were found, confirming both hypotheses. Perceptions of ethics based on racial-ethnic and position disparities, as well as the robust links with employee work features, offered potential avenues for decreasing disparities at work and improving the quality of long-term care. Noted further on ethics item scoring were relatively low scores indicating less involvement in, and access to, ethics discussions and decisions. In contrast, the literature review substantiated the importance of empowerment and retention, which were enhanced by employee involvement in work, notably, discussions and decisions. Thus, implications of ethics committees in long-term care sites as ways to potentially enhance employees' work and quality of care, especially work satisfaction and retention, were explored; relevant concerns raised by the Covid pandemic were, briefly, discussed.
\end{abstract}

Keywords Racial-ethnic $\cdot$ Job disparities $\cdot$ Ethics committees $\cdot$ Employees $\cdot$ Longterm care

Charlotte McDaniel

org.ethics@gmail.com

Extended author information available on the last page of the article 


\section{Introduction}

America's elder population is soaring. As they age, their need for health care increases. This paper explores research underscoring the multilayered role of ethics environments in facilities caring for elder persons in long-term care, especially for improving staffing conditions and retention of employees to enhance the quality of care.

Among the troubling concerns in long-term care organizations are staffing and retention of staff, also staff turnover. Indeed, turnover adversely interacts with the overall quality of care provided. For this reason the paper considers important work environment factors related to these employee concerns; they represent issues long-term care facilities continue to worry about and to address. In that regard, ethics analysis aids in highlighting and addressing several of these continuing concerns. Ethics, as used here, refers to the actions or decisions one ought to enact under considered circumstances (Beauchamp and Childress 1994). Put another way, what should be done when faced with challenging moral situations?

To offer context for this above exploration, national data highlighted the future, significant increases in the U.S. population expected among elder persons: Americans 85 and over were predicted to double to 8.9 million by 2030 (Wright 2005). Given that probable increase, there will be parallel demand for health care services offering high quality long-term care. However, providing consistent, quality care in long-term facilities were national, recognized, and continuing challenges (Allensworth-Davies et al. 2007). Among those challenges is the issue of staffing. Obstacles influencing staffing were illustrated, for example, by low employee retention, increasing work demands, complex care requirements, and difficult relationships between employees and supervisors (Donoghue 2014; Edwards 2005). These issues, typically and negatively, also manifest themselves in high turnover and low work satisfaction. Retention and turnover among staff are priority concerns.

Turnover becomes even more glaring when faced with the reality that, nationwide, direct care workers - typically certified nursing assistants (CNAs) - provided the majority of paid long-term care for elder persons (Donoghue 2014). To put a finer point on this critical issue, a recent Forbes (Quilter 2019) article addressing U.S. nursing home care reported CNA annual turnover was approximately $45 \%$. Turnover among CNAs, overall, was the highest among comparable occupations. Inversely, by 2030 workers were predicted to increase less than $10 \%$, creating a critical disparity among the long-term care workforce (Wright 2005). These statistics, documenting a shortfall among workers, corroborated those noted above on population increase and projected a continuing, significant stress on the long-term health care system.

Staffing issues are important to address since they are critical to quality of care. Studies that examined long-term care, for example, found staff turnover was related to reduced quality of care, whereas, reducing turnover was argued to increase quality (Buerhaus 2008; Zhang et al. 2014). Given earlier projections on population and worker changes, and the role of quality in care delivery, the quality component of U.S. health care is of significant concern. 
To enhance quality of care, research over the past several decades examines negative influences on staffing, as well as means to enhance staffing. Retention, noted earlier, was found to be associated with job satisfaction in long-term care, for instance (McGilton et al. 2013). In contrast, recent studies on staffing suggested probable underlying adverse contributors were found in racial-ethnic issues. Mack et al. (2020), for example, reported U.S. nursing homes were subjected to continuing institutional racial segregation. Corroborating results on racial disparities were reported by Maudlin (2020) among long-term care residents, representing elder adults and racial-ethnic minorities. Noted in this latter study, however, was the lack of systematic and uniform measure, making it difficult to garner a clear picture of these significant racial issues.

Continuing with racial concerns, nuanced examination of diversity suggests at the core of these concerns are dimensions of ethics characteristics in the work site. For instance, a nationwide study among nurses, adjusting for job characteristics, found possible lower job satisfaction was greater among nurses identifying as Black, compared to White; racial discrimination was reported among $13 \%$ of minority-identified home health aides (Lee et al. 2016; Xue 2015). Racial issues were barriers to quality work. Demographics were explored as factors influencing long-term care, affecting employee retention, work satisfaction, or interpersonal relationships (Hurtado et al. 2012; McGilton et al. 2013; Spetz et al. 2015).

Racial incongruence, for instance, between nursing staff and clients emerged as a factor in job strain among CNAs identifying as Black or White, immigrant or American born (Hurtado et al. 2012). The significant job strain, however, was between Black and White CNAs. Most immigrants also were Black, reporting less control in their work. Rather, plans to remain at work among nurses were related to abilities to garner decisions pertaining to ethics, a form of work control (McDaniel 1998). In contrast, organizational cultural sensitivity-including respect, diversity, and involvement with decision-making —was reported as a positive contributor, thereby reducing intention to leave among nurses (McGilton et al. 2013; Zhang et al. 2014).

In tandem with focus on staffing, a nuanced examination of the health workforce found, overall, it was becoming increasingly diverse (Snyder et al. 2018). Notably, persons of color were frequently represented among entry-level occupations; CNAs often identified as persons of color (Fabius et al. 2020). Truitt and Snyder (2020) found CNAs working in long-term sites experienced subtle and not so subtle workplace racism, emanating from supervisors, peers, and residents and leading to work stress. However, this study also noted few policies supported staff parity. Despite attempts to the contrary, reports revealed nursing home care continued to be highly racially segregated, but improving slightly (Li et al. 2015). Thus, considering the critical issue of staffing and the key role CNAs-often persons of color-play in long-term care, racial-ethnic issues represent central staffing concerns, ones not to be ignored.

Continuing with studies on racial-ethnic issues, a closer examination of diversity suggests at the center of several staffing issues are elements of the work environment raising ethics issues, among them racial-ethnic ones. Several themes and concepts emerge: respect, empowerment, decision-making, control, and job parity. These are central concepts. Indeed, they pertain to ethics. Respect, for instance, is tantamount 
to ethics. Ethics was argued as "foundational" to defining quality health care; the two were inseparable (Nelson and Gardent 2008). Respect also was a lingering issue among staff concerns, as was involvement in care decisions (Zhang et al. 2014). Ethics emerged also as a variable of interest for physicians and nurses, compared to other concepts representing desirable places to work, such as work effectiveness (McDaniel et al. 2006). A study of long-term care employees and ethics revealed positive results including plans to remain, confirming influence of ethics (McDaniel et al. 2010).

Indeed, ethics was an identified concept for long term care, tantamount to the delivery quality, as Bollig (2016) noted. The author noted it should be addressed; however, ethics was rarely examined among employees, including needed involvement of employees in ethical decisions. Related, were challenging relationships between supervisors and caregivers, focusing another ethical concern: interactions involve ethics (Galleta and Sparks 2012).

However, as important as these issues are for quality of care there have been few empirical studies of ethics in long-term care, especially pertaining to racial-ethnic concerns or job disparities. Indeed, in an ethical setting one would not expect significant racial-ethnic concerns nor job disparities reported among employees, much less discrimination and other adverse workplace issues. Ethical sites would be good places to work, to borrow a well-recognized phrase. Notably, Seavey (2004), among others, cited the need for research in ethics, establishing links between quality, turnover, and ethics in long-term care (Lesandrini and O'Connell 2016). Thus, the lingering questions are what are employees' perceptions pertaining to ethics and do they reveal racial-ethnic or job disparities; whether similar links to those cited above will emerge for work features-illustrated, for example by work satisfaction-on ethics. This study explores those queries among long-term care employees.

\section{Methods}

\section{Purpose and Hypotheses}

Using survey methodology, the purposes of this cohort cross-sectional study were to assess two hypotheses: (H01) racial-ethnic identity and job position disparities would emerge as significant factors $(p<0.05)$ in relationship to ethics, and (HO2) positive, significant relationships $(p<0.05)$ between ethics and employees' work features (i.e., manage disagreements, opinions of long-term care with intention to remain, work effectiveness, and work satisfaction) would be found on ethics. Demographic data supported base-line, differential analyses on relevant groupings.

\section{Participants, Sample and Recruitment}

Selection criteria included employees working a minimum of thirty (30) hours per week. This resulted in two hundred and seventy five (N275) employees as potential volunteers across six categories: administration, dining, housekeeping, maintenance, 
nursing, and other. Other was categorized to protect respondent identity in positions with less than five employees (e.g., chaplain). Also, since the study was attitudinal, any worker who was not employed more than thirty days prior to data collection was excluded to ensure minimum opinion formation (Selltiz et al. 1976). Self-selected racial-ethnic identity used the U.S. Census Bureau categories.

Recruitment of employees meeting stated criteria was initiated with a support letter from administration, also noting the volunteer status. A follow-up letter was sent to all employees by the Research Team detailing procedures, including informed consent, Institutional Review Board (IRB), and Research Committee approval.

\section{Materials}

Instruments were established and previously administered, including pre-testing among long-term care employees (Shortell et al. 1992; McDaniel et al. 2010). Cronbach's alpha coefficients ranged from 0.85 to 0.96 ; other psychometric qualities obtained, including validities and reading level. Each instrument used 1-5 Likert-type format (5 high) with strongly agree, strongly disagree wording for ease of comparison. Each questionnaire item also offered a "prefer not to respond" (PNR) option.

Socio-demographic data on employees, including self-selected racial-ethnic identity and work positions, were obtained on a one-page form. This demographic form was previously tested.

Ethics was measured on a scale previously detailed and reported, including extensive psychometric properties; reliability in health care ranged from 0.92 to 0.97 (McDaniel et al. 2006). Work features employed four scales: manage disagreements, opinions of work, including intention to remain, work effectiveness, and work satisfaction. Completion time for the research packet was pre-tested at twenty (20) minutes with 8th grade reading level, appropriate for the target population.

Definitions of the variables were, briefly: ethics environment reflected employee's perception of $\mathrm{h} / \mathrm{her}$ work setting regarding its ethical dimensions. Ethics was understood generally to refer to the studied decisions or behaviors of employees as they considered what ought to occur, those actions or decisions that should take place reflecting ethical dimensions as viewed in a moral life (Beauchamp and Childress 1994); ability to manage disagreements was defined as ability to address and resolve conflicts emerging at work among employees; attitudes of employees regarding their long-term care work, including intention to remain at work, comprised opinions about their care work delivered; work effectiveness reflected perceived ability to address the stated goals of the work unit or effectiveness; and work satisfaction was the perception of the employee for $\mathrm{h} /$ her pleasure with current work. The four work features were previously selected based on documentation of their signal contributions to quality health care organizations and delivery; they provided corroborating data for the influence of ethics (Shortell et al. 1992). 


\section{Procedures}

IRB and Research Committee reviews approved the (exempt) study for anonymous data collection with no identifiers or codes. Participants' cover letter served as informed consent, while aggregate data presentation added to confidentiality. A PRN option for each scale item extended protection. Employees completed paper and pencil questionnaires during work, on-site in one session of their choice, but within a set two-week time frame. The latter allowed for sick days, vacations, and time-off. No link was allowed between respondents' participation and supervisors regarding employee participation - or non-participation - to further protect employees from potential adverse effects. Administrators had no access to respondent data, preview of reports, or potential publications.

Following assessment for (few) missing data, statistical analyses were conducted with SPSS and SAS (Code: SAS 9.2). ANOVA and Pearson Product Moment Correlations assessed HO1 and HO2, respectively (Selltiz et al. 1976). Confidence levels were set at $p<0.05$.

\section{Limitations of the Study}

The primary limitation of the study was the use of one facility, also delimiting the population and constraining sample size. Location of the facility was the mid-Atlantic region of the U.S., which should be considered in extrapolation of results to differing regions or countries of long-term care employees. A secondary limitation was the use of quantitative data or questionnaires without supplemental qualitative data or interviews. This was due to concern for the length of time it would add to data collection, as well as for confidentiality. However, this limit, as well as use of anonymous data collection with no coding, also constrained follow-up among participants. The latter was considered an appropriate trade-off between confidentiality and potential response rate, and, data collection and extended time during work.

\section{Results}

\section{Participation and Response Rate}

Of the two hundred seventy five (N275) eligible employees, one hundred forty (N140) participated, resulting in a response rate of $50.9 \%$, which did not meet the $70 \%$ criterion (Selltiz 1976). Thus, comparison $(p<0.05)$ was conducted between the respondent sample and population on two confirmed variables (i.e., Human Resource Office). The population had a gender ratio of $25 \%$ males and $75 \%$ females, which was not significantly $(p<0.05)$ different from male respondents and the same proportion as females. Further confirmation was attained on age, where the sample and population were not statistically significantly different. Therefore, the 
respondent sample was deemed representative of this employee population. If more than $5 \%$ of instruments were left blank, the scale was deleted. Cronbach's alpha coefficient was 0.90 .

\section{Demographic Data}

Demographic data obtained on the respondents revealed no unusual responses, including analyses for cohort effects. For example, results on age, gender, marital status, and racial-ethnic identity were similar to those reported in other studies among long-term employees. In addition, the mean age and employment of respondents were 45.6 and 5.8 years, respectively, with no unusual standard deviations (S.D.) found.

\section{Ethics Scores}

As displayed on Table 1, the mean score on ethics was slightly above average (i.e., 3.16). In this sample a constrained range also was displayed; however, the upper range was relatively high (4.6), but not the maximum of 5.0. Following establishment of basic statistics, ethics items were computed. Below average scores were found on items pertaining to involvement in ethics decisions and reports of ethical concerns. HO1 was affirmed.

Table 1 Employee mean scores on ethics and work features

\begin{tabular}{lccccc}
\hline Measure & Nu* & Mean & S.D & Min. $^{+}$ & Max. $^{+}$ \\
\hline Ethics environment & 137 & 3.16 & 0.58 & 1.63 & 4.60 \\
Opinions of work & 137 & 3.52 & 0.67 & 1.71 & 5.00 \\
Manage disagreements & 137 & 4.12 & 0.55 & 1.85 & 5.00 \\
Work effectiveness & 137 & 3.52 & 0.67 & 1.71 & 5.00 \\
Work satisfaction & 135 & 3.29 & 0.46 & 1.80 & 4.31 \\
\hline
\end{tabular}

*Numbers are less than sample (N140) due to PNR responses

${ }^{+}$Respondents' minimum \& maximum mean score out of the possible $1-5$ range

\section{Racial-Ethnic Identity and Job Position}

In relationship to ethics, racial-ethnic background revealed a statistically significant $(p<0.05)$ difference among workers regarding perceptions of their ethics environment (HO1, Table 2); scores ranged from 3.04 to 3.55. Those self-identifying as African-American scored lower (3.04) than others, especially Caucasians or AsianPacific Islanders; the latter scored ethics highest (3.55), a statistically significant difference $(p<0.05)$. Native Americans were categorized as Other due to small numbers $(\mathrm{N} 3)$. Employees selecting PNR scored significantly $(p<0.05)$ lower at 2.70 , also revealing increased responses. PNR was noted, briefly, under "Discussion". 
Table 2 Analysis of variance of employee racial-ethnic group on ethics

\begin{tabular}{lll}
\hline Racial identity & $\mathrm{Nu}$ & Ethics mean score \\
\hline African-American & 41 & $3.04 * *$ \\
Asian-Pacific Islander & 05 & 3.50 \\
Caucasian & 87 & 3.30 \\
Other* & 06 & $3.00^{* *}$ \\
Prefer not reply (PRN) & 07 & $2.70^{* *}$ \\
\hline
\end{tabular}

*Native Americans (N3) were categorized as Other to protect their identity

**Actual $p<0.0387$; F Value 2.425; Total $\mathrm{N}=137$ due to PNR use

Analysis of variance revealed (Table 3 ) that employees' perceptions of ethics differed statistically significantly $(p=0.0001)$ based on employment position. Scoring ranged from a high of 3.62 to a low of 2.95 for Administration and Nursing Service, respectively. Other, which included categories with few employees, was 3.34. PNR scores were low (2.80).

Table 3 Analysis of variance of employee work position on ethics

\begin{tabular}{lll}
\hline Employment position & $\mathrm{Nu}$ & Ethics Mean score \\
\hline Administration & 19 & 3.62 \\
Dining & 26 & $3.06^{* *}$ \\
Housekeeping & 13 & 3.33 \\
Nursing service & 38 & $2.95^{* *}$ \\
Other* & 27 & 3.34 \\
PNR & 14 & $2.80^{* *}$ \\
\hline
\end{tabular}

*To protect identity, maintenance workers (N4) were listed as Other $* * p<0.0001 ; F$ Value 6.23; Total $\mathrm{N}=137$ due to PNR selection

\section{Employee Work Features, Scores}

Results on Table 1 also displayed mean scores with related statistics on the four (4) employee work features. The number $(\mathrm{N})$ of respondents differed slightly due to deletion of PNR. Details were presented, below:

\section{Ability to Manage Disagreements}

Ability score (4.12; Table 1) was the highest among the four (4) work features, with a range of maximum 5.0. One question, for example, noted co-workers were 
able to resolve conflicts among themselves in a relatively collegial manner, rather than relying on supervisors.

\section{Opinions of Work in Long-Term Care}

Opinion asked employees to rate perception of their work in long-term care, including plans to remain. Respondents' mean score (3.52; Table 1) substantiated above average opinions. Score range included the maximum.

\section{Work Effectiveness}

Effectiveness measure asked respondents to comment on their ability to meet their stated work goals - the overall mission. Based on the mean score (3.52; Table 1), employees in this study perceived themselves to be meeting the objectives of the facility. Scoring employed maximum range.

\section{Work Satisfaction}

Satisfaction mean score (3.29; Table 1) confirmed employees were slightly positive regarding satisfaction with work. Score range was more constricted than other scores, however.

\section{Ethics and Work Features, Correlations}

In order to assess significant relationships between ethics and work features, Pearson Correlations were established $(p<0.05$; Table 4$)$. Ethics was statistically significantly $(p<0.05)$ related to the four $(4)$ work features: manage disagreements, opinions of work in long-term care, work effectiveness, and work satisfaction. The relationship between ethics and work satisfaction was extremely robust $(0.76 ; p<0.0001)$, whereas, the relationship between ethics and managing disagreements was the lowest $(0.26 ; p<0.0028)$. HO2 also was confirmed.

Table 4 Pearson correlations between employee scores on ethics and work features

\begin{tabular}{lcclll}
\hline Measure & 1 & 2 & 3 & 4 & 5 \\
\hline 1. Ethics environment & - & & & & \\
2. Opinions of work & $0.65^{*}$ & - & & & \\
3. Work effectiveness & $0.62^{*}$ & $0.60^{*}$ & - & & \\
4. Managing disagreements & $0.26^{* *}$ & $0.35^{*}$ & 0.17 & - & \\
5. Work satisfaction & $0.76^{*}$ & 0.78 & $0.68^{*}$ & 0.29 & - \\
\hline
\end{tabular}

$* p<0.0001 ; * * p<0.0028$ 


\section{Discussion}

\section{Ethics Scoring}

Discussion addresses the two hypothesized findings and-briefly-the results on PNR. Also explored are the significant implications emanating from the results and their associated concerns, especially for ethics committees. The mean ethics score (3.16; Table 1) reveals a slightly positive ethics rating, implying these respondents have a relatively good ethics opinion of their workplace. However, the study scores are lower than those previously reported among long-term care employees (i.e., 3.32; McDaniel et al. 2010). Even so, scoring implies respondents are, overall, affirming; they perceive the site to be somewhat attentive to ethical concerns.

Further, the ethics scoring suggests a workplace these employees like and where they would remain. Respondents in this study experience a modicum of respect and they perceive policies are followed. In addition, they perceive modest supervisory support. However, further analyses of ethics items reveal access to ethics discussions and decisions are rated somewhat low, confirming their desire to access ethics discussions and decisions. Lower scores are important to note, given several studies citied the significance of examining ethics in long-term care; empowerment, decisions, and control, for example, were especially important for long-term care employees and their retention (Bollig et al. 2016; McGilton et al. 2013; Truitt and Snyder 2020; Zhang et al. 2014). Thus, these results signal implications for development of ethics committees, detailed below.

\section{Racial-Ethnic Identity}

Although the ethics aggregate score is above average, albeit slightly, one advantage of empirical ethics is the ability to ascertain dimensions of work needing attention. There are, of course, exceptions to aggregate scoring.

For example, analyses of demographic data reveal significant differences by employees' self-identified racial-ethnic group, suggesting certain employees perceive themselves to be working in less than an ethical setting. Or, some groups think the site is more ethical than others, noting the perception of ethics is not uniform throughout the facility. Ethical differences clearly prevail. While unmeasured, per se, as noted earlier, these results reveal potential racial concerns or uneven implementation of personnel policies (Mack et al. 2020). They may imply differential treatment or outright discrimination, even overt racism, as reported by Maudlin (2020). Regardless, differential scores suggest more attention to diversity to attain a desirable workplace.

Rather, robust ethics scoring would suggest little, if any, substantial differences among racial-ethnic groups. As noted by Truitt and Snyder (2020), racial diversity would be affirmed, in contrast to the racial differences reported by Fabius (2020), and as these study findings confirm. Likewise, robust ethics sites might be described as culturally competent, exhibiting respect, for example; the latter, critical for 
long-term care and desired (Zhang et al. 2014). Where strong ethics scoring was found, nurses also confirmed plans to remain, and reported supervisors who supported their employees (McDaniel 1998). Support, however, did not imply agreement; rather it implied one who listened well and acted on ethical concerns. Results of this study suggest otherwise. However, Galetta (2012) reported supervisory relationships as significant. Indeed, racial-ethnic disparities also highlight implications-discussed later-for long-term care ethics committees.

\section{Employment Position}

Disparities also are revealed among employment position(s) on ethics, with nursing service scoring (slightly) below average. Further, these scores were lower than scores reported among hospital nurses (McDaniel et al. 2006). Nursing scores in this study are also lower than administration, the latter closer to the institutional "core." Understandably, administrators-who may develop policies-have more positive opinions regarding ethics than others, as revealed among business employees (McDaniel et al. 2001). This is especially true when one considers administrators may rate their own work. "Rosier at the top" describes such a phenomenon.

Regardless, the aim is for all employees to share in positive perceptions of an ethics work site, albeit, with minor differences. A modicum of ethics is expected throughout the organization, illustrating ethical consistency and respect. This was especially critical when one recognized the majority of direct service in long-term care was provided by CNAs - front-line workers-many of whom were persons of color (Buerhaus 2008). Thus, desired is a consistent, dense ethics environment in which all employees, regardless of position-or racial-ethnic identity-and including CNAs, perceive respect and justice, both of which are components in ethics environments.

\section{Employee Work Features}

Clearly important are findings that ethics is associated with the four work features, confirming the second hypothesis. These select work features, as earlier cited, were identified in prior research regarding efficacious and high quality care systems. Each feature was central to the quality of work and care (Shortell et al. 1992). Thus, if ethics is related to these features it not only substantiates the importance of ethics in health, it highlights ethics in association with high performing systems, a desirable outcome. To further make the point, based on prior research, and corroborated by these study data, where ethics is positive, one anticipates ability to manage disagreements and effectiveness in meeting goals. Employees reported work satisfaction and positive opinions of their care delivery, including plans to remain, the latter identified as a critical component for long-term care (Spetz et al. 2015; Yeatts et al. 2018). Indeed, these features are core characteristics of desirable employment and high performing organizations. Therefore, their robust association to ethics suggests ethics is an integral component of quality health sites. These findings also obtain for long-term care. 
A caveat should be noted. Association does not imply causality, but rather important links between the variables of interest, revealing anticipated relationships between ethics and these central work features. Therefore, with perceived ethics one anticipates positive work features, as well as suggestions of quality, high performing sites. Rather, if ethics is negatively reported, one anticipates higher turnover among employees who are less satisfied, have lower opinions of their work, and are less effective. They demonstrate less ability to manage disagreements and conflicts. However, positive associations between ethics and work features are significant and very desirable.

\section{Effectiveness}

Important among the four work features is the ability to attain work goals or effectiveness, which score is relatively high (3.52; Table 1). As revealed in studies of health care delivery teams, effectiveness at work was a critical attribute to completing tasks important to the essential care work (Shortell et al. 1992). Getting the work done, accomplishing the tasks at hand, and completing daily jobs, among others, are central to accomplishing the facility's mission. It is a core component and a highly desirable feature of quality work. Results of this study reveal employees perceive themselves to be addressing the assigned work and doing so relatively well. This result was particularly seminal in light of reported concern for staff-patient ratios and increasingly complex tasks (Edwards 2005). These results reveal effectiveness is strongly associated with ethics ( $r$ 0.62; Table 4 ). Robust correlations imply these workers perceive themselves as effective in their work, accomplishing tasks, and supporting care quality in tandem with ethics. Indeed, ethics is associated with higher productivity, a very desirable finding.

\section{Managing Disagreements}

Disagreements at work are ubiquitous and inevitable. The question, then, is not whether conflicts occur, but rather how well they are managed. Similar to prior research where employees managed conflicts in health services and addressed them well, employees of this study think they manage their disagreements well; highest rated of the four features (4.12; Table 1; Shortell et al. 1992). Ability relies on good communication, implying inter-professional communication among team members. These scores also corroborated mean scores reported in long-term care (McDaniel et al. 2010). Likewise, where ethics was related to ability, employees worked as a team in a more collegial manner. Managing disagreements was tantamount to completing tasks and addressing work goals. Workers spent less valuable time in conflicts and disagreements, thereby enhancing their morale and work satisfaction. Thus, employees think they are able to manage their disagreements and in a constructive manner.

Ironically, while managing conflicts is highly scored and linked to ethics it is less robust than other features ( $r$ 0.26; Table 4). The mean score is highest, whereas, the link with ethics is the lowest coefficient. This association could be reflective of the reports on racial-ethnic and job disparities, indicating areas where teamwork, 
collegiality, and respect should be addressed. If the disparities revealed here permeate the environment, as suggested by these scores, it would adversely influence managing disagreements where racial or job differences are involved.

Ability to manage conflicts also enhanced self-esteem and control, an important feature noted earlier for staff retention and work satisfaction (McGilton et al. 2013; Truitt and Snyder 2020). It has implications for ethics committees, explored later. When conflicts occur, employees will attend to them. Issues are resolved in relatively short time. Conflicts do not linger nor are they allowed to "fester" at work. Rather, if workers are "sidelined" by constant disagreements, it detracts from their core work. Management of conflicts, thus, is central to care quality. It could potentially interact with ability to address underlying disagreements, even tensions resulting from lack of cultural competency, or overt and perceived discrimination, implied by revealed racial-ethnic disparities. Therefore, ability to manage conflicts with extant ethics at work has strong implications for enhancing the work setting, but also buffering tensions or issues emanating from racial-ethnic concerns and job disparities.

\section{Work Satisfaction}

Work satisfaction - with established link to retention-is robustly related to ethics $(r$ 0.68; Table 4). Revealing another contrast, however, work satisfaction is the lowest mean score among the work features (3.29; Table 1), but the most robust coefficient associated with ethics. Scores suggest these employees perceive several aspects of their work less satisfactorily, compared to other features. The reported racial-ethnic and job disparities may well adversely influence those scores. However, the robust link with ethics also implies ethics is an important influence on their perceived work satisfaction. Where employees are pleased with ethics, corroborated by ratings on work opinions and effectiveness, their overall satisfaction also would be higher. Rather, if ethics is rated low(er), one expects lower work satisfaction, perhaps with plans to leave-turnover.

Staff stability is a critical issue. Based on the reported importance of work satisfaction by Allensworth-Davies (2007), and the reported link with retention, these study results highlight the influence of work ethics. This is largely due to links between ethics and satisfaction and, thus, retention; work satisfaction influences retention. Creating robust ethics settings holds potential for satisfaction and retention, the latter also reported among national concerns for financial stability among health workforces (Buerhaus 2008). Thus, study results confirm the potential for ethics sites to sustain satisfaction in long-term care, and to influence, indirectly, retention.

\section{Opinions of Work}

Not only do these employees perceive conflict management, work satisfaction and effectiveness, they also have positive opinions of their care given. Based on the robust link with ethics ( $r 0.65$; Table 4$)$, they also plan to remain at work. The aggregate scores on opinions of work suggest a positive perception among employees 
regarding their long-term care provided to residents, including intended plans to remain at work.

The study scores on opinions of work, however, are slightly lower (3.52; Table 1) than those reported previously in long-term care (3.85), but higher than their perceived ethics score (3.16; McDaniel et al. 2010). These scores may have been influenced by the differential opinions of ethics based on racial-ethnic or work group disparities. However, overall, the opinion scoring, including plans to remain at work, implies these employees affirm their resident care services, tasks previously reported as increasingly complex (Edwards 2005). Caregivers perceive themselves as working well with residents. Thus, affirmation of care opinions is a criterion finding, since opinions may directly influence resident care, and intention to remain, the latter a signal staffing issue. In concluding remarks on the four work features, they reveal overall positive perceptions among employees and as they pertain to ethics environments. Such environments would also be culturally competent and good places to work. More importantly, however, since they were identified by Shortell and colleagues (1992) in high performance, quality sites, they thereby corroborate evidence of ethic environments as high performing and desirable places to work.

\section{PNR Results}

Lastly and briefly, respondents selecting PNR options were more numerous than in prior studies (McDaniel 1999; McDaniel et al. 2006). While PNR replies for racialethnic remain relatively small (N7), replies on job position are large(er) (N14), displayed on Tables 2 and 3. Comparatively, however, both numbers represent increased use. These increases corroborate concern for potential problems in the workplace. For example, anecdotal reports suggest choosing PNR may conceal respondents' identity due to lack of trust, or concerns about offering candid responses; issues with supervisors or administrators also may be worrying. These findings, albeit relatively minor, further imply an environment benefiting from attention to its ethical dimensions, including use of potential ethics committees.

\section{Concluding Implications}

\section{Hypothesized Results}

The significant differences among racial-ethnic groups and position disparities are buffered by the positive, robust links between ethics and the four work components, as well as the above average ethics scoring revealed in this study. These findings confirm the two hypotheses, leading to the conclusion that further examination of the site would be beneficial, especially pertaining to staffing. These results, however, also corroborate cited studies. The results on diversity substantiate, again, the importance of examining ethical characteristics in the work setting. For instance, longterm care workers, especially CNAs, stated concerns about increased job strain, lack of respect, as well as lingering racial issues (Hurtado et al. 2012; Mack et al. 2020). 
Studies reporting the demographics of CNAs in front-line positions found racial discrimination (Lee et al. 2016). Likewise, workers' relationships with supervisors were important for plans to remain at work, or retention (Stone et al. 2016; Galleta and Sparks 2012). These challenges, including racial and job disparities, highlighted the need to identify desirable long-term care places where employees felt good about their work (Edwards 2005; Fabius et al. 2020). Moreover, these results demonstrated the identified need for ethics analyses in long-term care, affirmed by Seavy (2004) and Lesandrini (2016) and found in this paper.

Rather, facilities exhibiting extant ethics environments support ways to address challenges and illustrate best practice sites. They imply fair treatment and respect of persons regardless of demographics or position. Conflicts are better managed and quality of care is anticipated to be evident, along with employee retention. Because of previously_and current-established links between ethics and work features, desirable sites illustrate ethics as well as the behaviors illustrated in the four work features outlined earlier; retention would follow.

Therefore, where ethics is positive these work features also are positive suggesting ethics environments are tantamount for high performing workplaces. Additionally, based on these results one would conclude that revealed disparities clearly need to be addressed in order to enhance staffing. Methods to enhance ethics have been previously identified and discussed (McDaniel 2004). Thus, one conclusion of this study is that if administrators of long-term care facilities want to encourage the essential caring work and staff stability, one probable way is to enhance the ethics environment-attend to ethics. Indeed, these results represent new data, linking racial-ethnic and job disparities with ethics, building upon and extending prior work to support ethics in long-term care.

\section{Unanticipated Results}

As illustrated in this study, empirical ethics provides data highlighting areas for prevention, intervention, or training to redress the many worrisome staffing concerns cited earlier and influencing quality of care. Thus, while unanticipated-not hypothesized-the results of item scores on ethics environment imply potentially significant consideration of an historical issue, heretofore, unfulfilled: development of ethics committees in long-term care. For instance, item scores pertaining to ability to address concerns, especially to access ethics discussions or decisions, are among the lowest. Scores imply workers have limited access to discussions concerning their work, including ethical concerns. Involvement is limited. Studies cited earlier clearly substantiated the argument for more employee involvement in work-related decisions and discussions, important employee corollaries for quality in long-term care, as well as employee retention and work satisfaction (McGilton et al. 2013; Truitt and Snyder 2020; Zhang et al. 2014). Involvement was also identified as a means to redress needed respect and empowerment among long-term care workers. Bollig et al. (2016) were more specific, citing need for more attention to ethics discussions, while Seavey (2004) argued for more research on ethics. Indeed, such involvement was earlier addressed. Study results, however, are new and fruitful data upon which 
to build. Thus the unanticipated results of this study - as new empirical data-corroborate those of earlier research and affirm the need for more employee involvement in ethics discussions and decisions with potential for enhancing quality of care.

\section{Ethics Committees}

Continuing the above implication for long-term facilities to develop ethics dimensions, it is relevant to consider probable roles they might serve. Historically, the Joint Commission for Accreditation of Healthcare Organizations (JCAHO 2020) identified three functions or roles: case review, education, and policy formation. However, these may also raise concerns for other considerations: prevention, intervention and training. Emerging facility needs that may intersect with case review or education may arise, for example. Thus roles and needs may intermingle. Regardless, ethics modalities may serve important roles and needs identified among national long-term facilities.

Additionally, comment on terms might be useful. JCAHO (2020) highlighted committees to address ethics concerns in healthcare organizations several decades ago. The majority were hospital ethics committees (HEC). Over time, however, these important entities evolved as did the Commission mandate, later referencing an ethics mechanism providing a more tailored response. Mechanisms also may be illustrated by committees. Regardless, this study suggests long-term ethics modality (LTEM). Indeed, rather than an organizational entity illustrated by a committee, per se, we identify mechanisms, recognizing the terms and structures may vary. They may illustrate action(s) implementing ethical discussion and analysis relevant to particular facilities. We encourage this development to consider several of the worrisome staff concerns explored earlier among long-term facilities.

Indeed, there are considered reasons for suggesting a tailored approach. The earlier mandate for committees was seldom implemented in non-hospital facilities; there was no regulatory requirement for skilled nursing facilities, for example (Nichols 2007). Regardless, JCAHO accreditation extended to nursing homes; ethics committees were not limited to hospitals (Zivot 2020). These assertions were corroborated by surveys among long-term facilities: only $2 \%$ had a committee or mechanism and those that did seldom met (AMDA 2008; Nichols 2007). It is time to consider an ethics modality in non-hospital facilities to enhance staff work and retention, as well as resident care. However, practically, to be encouraged is an ethics modality, illustrating considered ethical actions or analyses, rather than assuming a formal entity, per se. Long-term ethics modalities also have potential roles or address different needs. First, for instance, long-term compared to acute sites have differing staff demographics; staff-patient ratios are larger. Acute care patients and their loved ones parallel that status, often remaining in the care facility for a limited time frame; they anticipate return home. In contrast, in long-term care, residents may be there permanently, while potentially offering long-term relationships. Obviously, length of stay may lead to differential relationships between staff and patients. Increased stay means staff may become more like "family." Patients' loved ones, typically, have more staff involvement. Demographically, acute care staffs tend to be occupationally 
diverse with more registered or practical nurses and physicians, for example. Lastly, in other health sites the assumption is patients will improve and return home; rather, in long-term that is rarely the case, thus altering the dynamic of care. Thus, LTEM could offer patients and their loved ones representation not typical, especially as a less professionalized setting. They offer opportunity for employee involvement, including discussions and decisions pertaining to their care work. These new study results substantiate LTEM's potential, positive influence on sites. LTEM represent ways to engender control or empowerment among employees. Such avenues would be available to all employees.

Other potential roles obtain. Second, the level of reported abuse in long-term care far exceeds that of the acute care setting; the need is greater for attention to abuse and neglect, for example. Thus the ethics committee may serve as a barometer for these national concerns. Third, there is great potential also for education of staff and residents, which function is one of the three noted in the original development of hospital ethics committees. Staff education about ethics would serve not only for intervention, but for preventive measures in long-term sites. Fourth, the LTEM retains a more collegial and constructive ambiance in the facility, in contrast to the use of (external) Hotlines, typically available for significant complaints. It also holds the potential to diffuse conflicts that may emerge among staff or between staff and administrators, a desirable aim. Lastly, the need for staff to have access to sources of decisions, discussions, support, or education may be served by the ethics committee. All of these portray an important role for ethics committees in the long-term care facility. Others may emerge in the future.

Without restating the obvious-the prior cited research and study results offer rationale and need for LTEM - it might be beneficial to briefly note other concerns and needs LTEM might address: enhance staffing and reduce turnover, also resulting in more financial stability cited by Buerhaus (2008); improve work satisfaction, known to be a signal component of any workplace; or increase needed respect and empowerment through LTEM involvement. These were highlighted in cited studies. Additionally, LTEM hold the potential to give voice to workers who might otherwise be ignored. In that regard an ethics mode could provide more fair and just representation across long-term staff in discussions about their resident care. This, too, is a form of empowerment. They offer opportunity for staff engagement among those not perceiving respect. Anecdotally, long-term care staff do not perceive themselves as appreciated, in contrast to their clear need or contributions as health care personnel, noted during the pandemic (Hamill 2020). Thus, development of LTEM meets a need while addressing challenges prevalent among long-term employees. Ethical analysis allows discussions and some modicum of decisions regarding work, a clearly stated need.

Other reasons addressing needs also obtain. An alarming, yet, significant reason is the sensitive issue of abuse in nursing homes. A quick search revealed abuse continued, even increased, in U.S. nursing homes (Nursing Home Abuse 2019). Among the salient points made in this 2019 report were, summarily: annually, as many as 5,000,000 elders were abused; at least one instance of actual physical abuse was experienced by $24.3 \%$ of residents in nursing homes; only 1 in 14 elder abuse incidents were formally reported; figures were estimated as low, since many abuse 
victims were unable or unwilling to report their abuse; and lastly, data from Adult Protective Services (APS) noted increasing numbers of abuse reported in recent years. Indeed, these statistics are troubling, if not alarming. The latter issue was more concerning: increasing but unreported abuse. Thus, we do not actually know the current prevalence of abuse in nursing homes. It puts new meaning into the term vulnerable persons. However, LTEM may allow employees means to address work concerns on behalf of themselves or their residents. For instance, studies found discrimination - a consideration in abuse-was significant (13\%) among long-term employees (Lee et al. 2016; Xue 2015).

Another development reason is located in external factors. Summarily, they included more guidelines from external agencies; obligation to patient rights and protection of patients; federal and state privacy laws, including HIPAA regulations, a sign of professionalism (HCA 2019). Accreditation is available to aid in maintaining standards and policies, many of which pertain to and support patient care. Rather, media reported facilities not adhering to standards (Hamill 2020). These external factors pertain to ethics. They support employees. Thus involvement offered by LTEM including ethics analysis, aids in enhancing the overall workplace environment, moving it toward an ethics environment where policies are consistent.

Indeed, another signal reason to address LTEM is the influence of the Covid-19 pandemic. Media investigations shined a stark light on several seminal issues in long-term care (Hamill 2020). Among those most affected by this health care crisis, for instance, were those most vulnerable: elder residents of long-term facilities. Deaths among this vulnerable population were significantly and disproportional higher than in the general population: 55\% in Washington State and $42 \%$ in Brighton Nursing Home, to cite several (Washington 2020; Hamill 2020). Clearly, this pandemic brings into sharper focus negative influences of the crisis. If, however, ethics mechanisms were operational it may have afforded staff ways to raise the worrying issues they observed, and, noted below, reported in the media as the pandemic emerged (Hamill 2020).

Also and concerning, reports addressing the pandemic confirmed racial-ethnic and job disparities prevailed (Hamill 2020). They highlighted the hypothesized concerns, corroborating study results: racial-ethnic and job disparities prevail in long-term care. The majority of the staff, for instance, providing direct care-those on front lines-disproportionally represented persons of color. This highlights the continuing challenge for allocation of one scarce resource: trained, quality staff. The concern is exacerbated when reports also noted the lack of PPE, for example, thereby, disproportionally exposing minority staff. Clearly to be avoided are plans where front line workers are discriminated by assignment or risk level. Averting such perceptions is tantamount to enhancing the team work, morale, and overall efficacy of the health workforce.

In contrast, news reports regarding the pandemic detailed "missteps" illustrated in staff reduction, cuts in RNs, and shifts from full to part-time and agency personnel (Hamill 2020). Lack of training and staff monitoring, delayed response, and nonadherence to staff-resident ratios were noted. Communication-including interprofessional communication-lapses were notable. Ignoring state-national standards for room assignments leading to overcrowding was a signal issue. Such actions 
undermine quality care and exacerbate staff concerns. They are reminiscent of earlier cited issues. However, with LTEM staff may have means to address their quality care-and safety - concerns. Thus, the pandemic also highlights need for LTEM.

The pandemic also highlights ethics decisions for allocation of scarce resource such as PPE, valued staff, or vaccines, among the most challenging ethical decisions. Coordinated efforts could range from training and monitoring to allocation of scarce resources. Likewise, as the results of this study imply, avoiding racialethnic disparities to embrace team work would be essential. Where ethical parameters are implemented one would anticipate outcomes of this study: heightened ability to manage emerging conflicts and enhanced productivity, as well as more positive opinions of, and satisfaction with, the emergent work. Regardless, such ethical decision-making would best be put in place prior to an emergent event, including staff training so facilities are positioned to respond in a timely manner. Lack of response, slow, and delayed actions were national issues-noted earlier-exacerbating the viral spread (Hamill 2020). These decisions require equitable plans. Planning for prevention is essential, suggesting a possible role for LTEM. Indeed, the findings of this study could have been influenced by LTEM. For example, if a LTEM were active, employees perceiving racial-ethnic identity or job category disparities could have presented their concerns and requested examination of the issues. Such concerns are confidential and are required to be addressed. Ethics education about similar issues could be offered. Once noted, astute administrators could be alert to ensure parity in job assignments, an issue noted in the pandemic. It may allow the many CNAs expressing concern for lack of respect, needs for empowerment or discussions, to obtain the latter via access to extant ethics discussions. Finally, staff members concerned for their residents, also reported during the Covid pandemic (Hamill 2020), could have used LTEM to identify and raise their concerns.

Clearly, LTEM are not a panacea for all long-term staffing issues. Regardless, their implementation offers constructive, potential ways to address previously explored staff concerns (e.g.): ethics rounds or individual case studies, presentations and discussions pertaining to ethics and resident care; weekly or monthly ethics consultations, or monthly ethics meetings. Annual or monthly training or workshops pertaining to ethics could be offered addressing also required continuing education. Quality sites encourage learning and education. Thus, these strategies support employees as well as their quality of care.

Continuing with implementation, one query administrators might ask is about personnel. Ethics may imply expertise not commonly found in long-term facilities. Committees, however, as originally conceived by the JCAHO (2020) were designed to be representative. Thus, activities would best include different occupations, including among several administrators, CNAs, nurses, physicians, social workers, or other employees in long-term facilities. Committees also were required to have lay membership, suggesting members from the community or "consumer" population-a patient or a family member.

To continue with question of members and communities, the latter offer persons with ethics expertise. A classic example would be a local minister, priest, or rabbi, many of whom not only take courses in theology or religion, but also in ethics. Local 
communities have colleges in which persons educated in ethics could be present. Seminaries and departments of religion or philosophy are excellent examples. Pastors, as another example, were found to provide a significant and important, if not unique, role on ethics committees; they contributed well and professionally (McDaniel 1999).

Lastly, if one were to anticipate future research one might comparatively explore perceptions of workers' experiences or work assignments, balance in ratios of staff to residents, or access and support illustrated in appropriate PPE; facility support in training for a crisis, buffered by prompt and effective communication. Or, facility response times, rates of infection, or deaths in light of facility structures. Bed size, staffing ratios, resident and staff racial-ethnic backgrounds, and age of residents are relevant. Allocation of scarce resources could be included. While not an exhaustive list these factors rise to the top. Importantly, comparative analyses of for-profit and non-for profit facilities regarding several of these variables would be informative, especially as the differences were highlighted in media reports (Hamill 2020).

Especially relevant for this discussion, for instance, is comparative analyses of longterm care sites with and without LTEM; examination of the numbers and types of concerns raised and by whom. Indeed, especially fruitful would be assessment of the influences of LTEM on staff; their signal contributions to the workplace, and resident care. These data would be very informative for continuing development of LTEM, especially the latter, which fundamentally assesses the efficacy of LTEM, a significant analysis.

\section{Summary}

Ethical considerations illustrated in LTEM, therefore, may not result in a committee, per se, but a means by which employees may convey their ethics-related concerns and be assured they are addressed competently and confidentially. They may provide opportunity to address ethics concerns, identified earlier as significant among long-term care staff. Regardless of whether the means is a committee or mechanism each offers valuable contributions to long-term care sites and needs to be considered; each may respond to the reported needs of employees and facilities. Such activities contribute to the overall perception of a strong ethics environment and potentially redress the racial-ethnic and job disparities revealed here. They offer staff a means of involvement leading to their desired empowerment. Based on studies cited here, LTEM also hold the potential for enhancing staffing and staff stability, best illustrated in job satisfaction and retention of long-term care employees. Therefore, attention to ethics, and its related behaviors found in ethics modalities_-or committees or mechanisms — addresses the ultimate aim of enhancing long-term care quality.

Acknowledgements The authors would like to acknowledge the contributions of the late Prof. James K. Roche, PhD, MD, University of Virginia, for his seminal work on the initial phases of this project. 


\section{References}

AMDA (2008). Role of a facility ethics committee in decision-making at end of life. White Paper, Advance Care Planning, Bulletin of the Society of Post-Acute and Long-Term Care, March 1.

Allensworth-Davies, D., Leigh, J., Pukstas, K., Geron, S., Hardt, E., \& Brandis, G. (2007). Country of origin and racial-ethnicity: Are there differences in perceived organizational cultural competency and job satisfaction among nurse assistants in LTC. Health Care Management Review, 32(4), 321-329.

Beauchamp, T., \& Childress, J. (1994). Principles of biomedical ethics (4th ed.). Oxford: Oxford University Press.

Bollig, G., Rosland, J., \& Heller, A. (2016). How to implement systematic ethics work in nursing homes? Advances in Medical Ethics, 3(1), 1-9. https://doi.org/10.12715/ame.2016.

Buerhaus, P. (2008). Some potential solutions to high direct-care staff turnover rates. Journal American Medical Association, 300(20), 2422-2424.

Donoghue, C. (2014). The challenge of workforce retention in long-term care. Journal of Applied Gerontology, 33(1), 3-5.

Edwards, D. (2005). LTC employee turnover costs the nation billions every year. Nursing Homes: LTC Management Review, 54(2), 16-21.

Fabius, C., Wolff, J., \& Kasper, J. (2020). Race differences in characteristics and experiences of Black and White caregivers of older Americans. Gerontologist, 13, 1093.

Geletta, S., \& Sparks, P. (2012). Administrator turnover and quality of care in nursing homes. Annals of LTC, 21(2), 21-24.

Hamill, S. (2020). Brighton's Plight. Pittsburgh Post-Gazette, 94(106), A1.

Home Care Association. (2019). HCA clinical ethics manual. Boston: HCA Headquarters.

Hurtado, D., Sabbath, E., Ertel, K., Buxton, O., \& Berkman, L. (2012). Racial disparities in job strain among American and immigrant long-term care workers. International Nursing Research, 59(2), 237-244.

Joint Commission for the Accreditation of Healthcare Organizations (JCAHO, 2020). Author: Overbrook, IL.

Lee, D., Muslin, I., \& McInerney, M. (2016). Perceived racial discrimination among home health aides: Evidence from the national survey. Journal Health \& Human Service Administration, 38(4), 414-437.

Lesandrini, J., \& O'Connell, C. (2016). Commentary: The broader context of long-term care ethics. Cambridge Quarterly, 25(3), 554-556.

Li, Y., Harrington, D., Temkin-Greener, H., You, K., Cai, X., \& Cen, X. (2015). Deficiencies in care at nursing homes and racial/ethnic disparities across homes fell, 2006-11. Health Affairs, 34, 1139-1146.

Mack, D., Jesdale, B., Ulbricht, C., Forrester, S., Michener, P., \& Lapane, K. (2020). Racial segregation across U.S. nursing homes: A systematic review of measurement and outcomes. Gerontologist, 60(3), 218-231.

Maudlin, R., Lee, K., Tang, W., Herrera, S., \& Williams, A. (2020). Supports and gaps in federal policy for addressing racial and ethnic disparities among long-term care facility residents. Journal of Gerontological Social Work, 63(4), 354-370.

McDaniel, C. (1998). Ethics environments: Reports of practicing nurses. Nursing Clinics of North America, 33(2), 363-372.

McDaniel, C. (1999). Clergy contributions to healthcare ethics committees. HEC Forum, 11(2), 140-154.

McDaniel, C. (2004). Organizational ethics: Research and ethics environments. Aldershot: Ashgate Publishers Ltd.

McDaniel, C., Roche, J., \& Veledar, E. (2010). Ethics environments in long-term care. Journal of Applied Gerontology, 30(1), 67-84.

McDaniel, C., Schoeps, N., \& Lincourt, J. (2001). Organizational ethics: Perceptions of employees by gender. Journal of Business Ethics, 33(3), 245-256.

McDaniel, C., Veledar, E., LaConte, S., Peltier, S., \& Maciubu, A. (2006). Ethics environment, healthcare work, and patient outcomes. American Journal of Bioethics, 6(5), W17-29.

McGilton, K., Tourangeau, A., Kaveic, D., \& Wodchis, W. (2013). Regulated staff: Perceptions of nurses' intentions to stay in long-term homes. Journal of Nursing Home Management, 2(5), 771-781. 
Nelson, W. \& Gardent, P. (2008). Ethics and quality development. In Management Ethics Series. Health Care Executive, July/Aug, 40-41.

Nichols, J. (2007). The vital role of an ethics committee. Medical Ethics, 8(4), 14-15.

Nursing Home Abuse Justice, National Data. (2019). https://www.nursinghomeabU.S.e.org/nursinghome-abuse/statistics.

Quilter, D. (2019). What some nursing homes do to retain quality staff. Forbes, June 11. Next Avenue Contributor. https://www.forbes.com/sites/nextavenue/2019/06/11.

Seavey, D. (2004). The cost of front-line turnover in long-term care: Better jobs, better care. Princeton: Study funded by the Robert W. Johnson Foundation.

Selltiz, C., Wrightsman, L., \& Cook, S. (1976). Survey methods. In Research methods in social relations (3rd ed., pp. 417-419). New York: Holt Rinehart \& Winston Publishers.

Shortell, S., Rousseau, D., Gilles, R., Dever, K., \& Simons, T. (1992). Organizational assessment in ICUs: Construct development, reliability and validity of the ICU nurse-physician questionnaire. Medical Care, 29, 709-723.

Snyder, C., Frogner, B., \& Sillman, S. (2018). Facilitating racial and ethnic diversity in the health workforce. Journal of Allied Health, 47(1), 58-65.

Septz, J., Trupin, L., Bates, T., \& Coffman, J. (2015). Future demand for LTC workers will be influenced by demographic and utilization changes. Health Affairs, 34, 6936-6945.

Stone, R., Wilhelm, J., Bishop, E., Bryant, N., \& Hermer, L. (2016). Predictors of intent to leave the job among home health workers: Analysis of national home health aide survey. Gerontology, 56, 1-10.

Truitt, A., \& Snyder, C. (2020). Racialized experiences of Black nursing professionals and CNAs in longterm care settings. Journal of Transcultural Nursing, 31(3), 312-318.

Washington State, Department Health. (2020). Covid-19 long-term care report. http://www.doh.wa.gov/ Portals/1600/coronavirus/data-tables/Weekly-COVID-19.

Wright, B. (2005). Direct care workers in LTC (pp. 1-4). Washington, D.C.: AARP Public Policy Institute.

Yeatts, D., Seckin, G., Shen, Y., Thompson, M., Auden, D., \& Cready, C. (2018). Burnout among direct care workers in nursing homes: Influences of organizational workplace, interpersonal and personal characteristics. Journal of Clinical Nursing, 27(19-20), 3652-3665.

Xue, Y. (2015). Racial and ethnic minority nurses' job satisfaction in the U.S. International Journal of Nursing Studies, 52(1), 280-287.

Zhang, Y., Punnett, I., \& Gore, R. (2014). Relationship among employees' working conditions, mental health, leave intention in nursing homes. Journal Applied Gerontology, 33, 6-23.

Zivot, J. (2020). Useful ethics committees: No mandate required. Editorial, Critical Care Medicine, 48(6), 928-929. https://doi.org/10.1097/CCM.0000000000004357.

Publisher's Note Springer Nature remains neutral with regard to jurisdictional claims in published maps and institutional affiliations.

\section{Authors and Affiliations}

\section{Charlotte McDaniel $^{1}$ (D) Emir Veledar ${ }^{2,3}$}

Emir Veledar

eveleda@emory.edu

1 Faculty Scholar, Center for the Study of Law \& Religion, Emory University School of Law, Emory University, Gambrell Hall, Suite 310, 1301 Clifton Road, Atlanta, GA 30322, USA

2 School of Medicine, Emory University, Atlanta, GA, USA

3 Baptist Health South Florida, Miami, FL, USA 